\title{
O significado acional no discurso da Constituição Brasileira: o gênero discursivo normativo constitucional em questão
}

Ruberval Ferreira (UECE) Maria Clara Gomes Mathias (UECE)

\section{Resumo}

O estudo aqui proposto volta-se para a construção do gênero discursivo jurídico-normativo constitucional, a partir de sua dimensão ideológica, procurando compreender como o emprego de formas linguísticas particulares contribui para o estabelecimento e a sustentação de relações de dominação no interior do discurso e fora dele (THOMPSON, 2009). Toma-se como referencial teórico a compreensão da $A D C$ do discurso como um momento de práticas sociais, dialeticamente interconectado com outros elementos. Além da $A D C$, o presente estudo procura desenvolver um diálogo transdisciplinar com a pesquisa histórica do contexto em que foi gestada nossa atual Carta Magna, com o Direito Constitucional e a Teoria Geral do Estado, notadamente no que toca ao valor social e jurídico das constituições na contemporaneidade. Para a operacionalização da análise ora desenvolvida, tomamos como instância discursiva de análise a Constituição Federal de 1988, diploma normativo que inaugura o Estado de direito brasileiro, assim como adotamos como referência a discussão que Fairclough (2003) faz sobre a noção de significado acional e a categoria analítica estrutura genérica.

Palavras-chave: Análise de Discurso Crítica, significado acional, estrutura genérica, Constituição Federal. 


\section{Introdução}

A história das formações sociais é marcada por tensões, conflitos e confrontos de forças ou vontades de diversas ordens que configuram um mosaico de antagonismos sociais extremamente complexo. É uma história de lutas sustentadas por estratégias de linguagem que instauram ordens postas como necessárias e que raramente têm sua dimensão ético-política problematizada (FERREIRA, 2007). A Constituição brasileira é exemplo de um empreendimento discursivo que tem sua história fundada nessas mesmas tensões, que são sempre materializadas na linguagem.

O estudo aqui proposto volta-se para a construção do gênero discursivo jurídico-normativo constitucional, a partir de sua dimensão ideológica, procurando compreender como o emprego de formas linguísticas particulares contribui para o estabelecimento e para a sustentação de relações de dominação no interior do discurso e fora dele (THOMPSON, 2009). Para tanto, tomamos como instância discursiva de análise a Constituição Federal de 1988, diploma normativo que inaugura o Estado de direito brasileiro, por meio da fixação de uma ordem simultaneamente jurídica, discursiva e sociológica.

Nesse contexto, a perspectiva particular do discurso oferecida pela Análise de Discurso Crítica - ADC, em sua vertente mais proeminente, a Teoria Social do Discurso, de Norman Fairclough (2001; 2003), oferece elementos interessantes para pensarmos o objeto em questão. Toma-se como referencial teórico a compreensão da ADC do discurso como um momento de práticas sociais, dialeticamente interconectado com outros elementos. Partindo do paradigma funcionalista da linguagem, Fairclough (2003) postula que o discurso figura no interior das práticas sociais de três maneiras distintas, como formas de agir, como formas de representar e como formas de ser. Fornece, por essa via, um modelo de análise a partir de três tipos de significados - acional, representacional e identificacional. Para a operacionalização da análise ora desenvolvida, adotamos como referência a discussão que Fairclough (2003) faz sobre a noção de significado acional e a categoria analítica estrutura genérica.

Além da ADC, o presente estudo procura desenvolver um diálogo transdisciplinar com a pesquisa histórica do contexto em que foi gestada nossa atual Carta Magna, com o Direito Constitucional e a Teoria Geral do Estado, notadamente no que toca ao valor social e jurídico das constituições na contemporaneidade, assim como no que diz respeito a uma concepção culturalista da Constituição e do Estado, entendendo que o direito é fenômeno social e é norma. Impossível é a pretensão de separar um do outro (REALE, 2010, p. 7). 


\section{O contexto histórico da década de 1980 e a Constituinte de 1988}

Muitos historiadores situam, na década de 1980, um estágio de transformações geopolíticas profundas vivenciadas pelo mundo, ocasionando uma mudança de época. Pode-se dizer que, ao longo desta década, atingiu seu ápice um longo processo, que se estendeu desde o pós-guerra, de superação da idade industrial e início da era da informação ou pós-industrial. O modo de produção capitalista adquiriu um novo rosto, procurando conciliar o ímpeto voraz do mercado em meio às novas demandas do intercâmbio entre nações, com os anseios sociais e com a necessidade de um controle, mesmo que mínimo, do Estado sobre a economia. Todo este contexto produziu reflexos profundos sobre a sociedade brasileira.

Durante esta década, o Brasil busca acompanhar a tendência de proliferação de governos neoliberais vivenciada em todo o mundo. Esse direcionamento econômico, que se inicia ainda no período ditatorial, se estenderá durante o processo de redemocratização e será um fator fortemente determinante para a conformação da nova ordem jurídica inaugurada no Brasil com a promulgação da Constituição de 1988, notadamente no que diz respeito à ordem econômica e financeira adotada pelo Estado brasileiro.

Justamente por ser um período de superação de uma duradoura ditadura, o anseio por participação nos rumos do país era muito sentido em toda a nação. Nesse ínterim, a população foi mobilizada a interferir nos destinos do Estado. Um movimento emblemático do engajamento político popular que marcou a década de 1980 foi o chamado movimento das "diretas já". O povo brasileiro foi às ruas, em 1984, para exigir a volta das eleições diretas para presidente.

Dentro desse contexto de intensas transformações e de forte apelo popular, configurou-se o ambiente político-jurídico que deu origem à Assembleia Nacional Constituinte de 1987, nascedouro da Constituição Federal promulgada em 1988. As atenções e esperanças dos brasileiros voltaram-se para esse momento histórico de instituição de uma nova ordem jurídico-constitucional no país. Havia um desejo de que ela não só fixasse os direitos dos cidadãos e os institutos básicos da nação, mas também fosse a fonte para solução de uma série de problemas que marcavam a sociedade brasileira àquela época e que estavam, contudo, muito fora do alcance das matérias de uma Constituição (FAUSTO, 2008, p. 288).

Jorge Miranda, notável constitucionalista português, ao elaborar um extenso histórico dos sistemas constitucionais mais proeminentes de todo o mundo, dedica uma seção do seu estudo ao constitucionalismo brasileiro. Esse autor, ao fazer sua análise 
da evolução histórica das constituições brasileiras, afirma que o período que se estende desde 1930 até a Constituição atual apresenta algumas notas características, alguns traços essenciais, que o autor reúne em três grandes aspectos: 1) evolução com soluções de continuidade e com frequentes crises político-militares; 2) sucessão, quase alternância de governos autoritários e de governos liberais e democráticos; e 3) proliferação de constituições (5 constituições desde 1934, contra 2 apenas desde a independência até este ano) (MIRANDA, 2002, p. 148).

De fato, a história do surgimento do poder constituinte originário, isto é, da necessidade de imposição de uma nova ordem constitucional, vem sendo acompanhada por quadros de grande turbulência, que trazem consigo a marca das revoluções. O Brasil, na condição de um país de dimensões continentais, que teve sua formação étnica e cultural marcada por intensa miscigenação, assim como uma formação política e econômica fincada numa posição de subordinação e dependência (seja do ponto de vista da colonização, seja no âmbito do subdesenvolvimento), não poderia ter o histórico de sua formação jurídico-normativa constitucional isenta dos influxos da complexidade social que o caracteriza historicamente.

Esta constatação traz, de imediato, uma importante consequência para a análise que propomos no presente trabalho. Se todos os atos políticos e jurídicos, porque linguísticos, comportam (ou até mesmo exigem) uma abordagem crítica que leve em consideração sua dimensão ético-política, tanto mais o será a Carta Magna de 1988. Isso porque esse documento de índole normativa de status superior possui como traço marcante de sua formação, conforme o percurso histórico aqui apontado procurou demonstrar, o confronto de forças e vontades opostas, a presença de disputas por poder fincadas em realidades históricas, enfim, a luta pela hegemonia dos sentidos (FERREIRA, 2007).

Ela pode ser considerada, portanto, uma produção cultural, tanto quanto a decisão política fundamental, que se consubstancia em texto e que atribui fundamento de validade para as demais normas do ordenamento jurídico. Uma das justificativas para a necessidade de uma incursão pela história diz respeito ao interesse de se afirmar, neste trabalho, a dimensão sociológica, culturalista e histórica do discurso jurídico-normativo, dos textos de lei. Todos eles, ao mobilizarem sentidos, ingressam na perigosa trama do discurso e se inscrevem no fluxo da luta hegemônica ou das lutas por representações.

\section{Breves considerações sobre o valor social e jurídico das constituições}

Segundo Bonavides (2001, p. 205): “o poder constituinte é essencialmente um poder de natureza política e filosófica, vinculado ao conceito de legitimidade imperante numa determinada 
época". As constituições tais como as conhecemos hoje surgem enquanto fruto de uma reivindicação revolucionária principalmente da classe burguesa, no século XVIII, para reposicionar esta legitimidade de que fala Bonavides - legitimidade de "constituir" e dar as feições do Estado-nação. Para a burguesia, essa legitimação situava-se não mais nas duas titularidades clássicas - a divina e a monárquica -, mas deveria ser entregue à nação, em um primeiro momento, e ao povo, posteriormente, com o advento das sociedades democráticas.

Para o constitucionalismo moderno, o chamado neoconstitucionalismo, a Constituição nas sociedades contemporâneas assume um valor normativo supremo, um status de superioridade, que não consiste em uma "verdade" inerente às constituições, mas sim em um valor social, político e ideológico, construto moldado na história de sua evolução, pelo empenho em aperfeiçoar os meios de controle do poder, em prol do aprimoramento dos suportes da convivência social e política. No presente da história, pode-se falar em superioridade constitucional, subordinação a ela de todos os poderes por ela constituídos, o que se manifesta exemplarmente nos mecanismos atuais de controle de constitucionalidade (MENDES \& BRANCO, 2011, p. 61).

Não se tolera a produção de norma contrária à Constituição, porque isso seria usurpar a competência do poder constituinte. Este, sim, passa a ser a voz primeira do povo, condicionante das ações dos poderes por ele constituídos. A Constituição assume seu valor mais alto por sua origem - por ser o fruto do poder constituinte originário (Ibidem, p. 55).

Dessa forma, podemos esboçar, neste ponto da discussão, um quadro preliminar do valor social e jurídico das constituições oferecido pelo Direito Constitucional. Atualmente, nos ordenamentos jurídicos dos países de regimes políticos de índole democrática, as Constituições caracterizam-se por seu status superior. Elas possuem supremacia por consubstanciarem o ideal máximo de representatividade e de expressão da vontade do povo, considerado o titular do poder constituinte, isto é, do poder de "constituir" o Estado, dar as feições da ordem que se sobreleva à nação. Para Bonavides (2001):

Nas formas democráticas a Constituição é tudo: fundamento do Direito, ergue-se perante a Sociedade e o Estado como valor mais alto, porquanto, de sua observância deriva o exercício permanente da autoridade legítima e consentida. Num certo sentido a Constituição aí se equipara ao povo cuja soberania ela institucionaliza de modo inviolável. E o povo, em sua potencialidade, numa acepção política mais genérica, deixa de ser unicamente o elemento ativo e militante que faz nas urnas, de modo direto, e nos parlamentos, pelas vias representativas, a vontade estatal, para incluir em seu raio de abrangência toda a nação como um corpo de ideias, sentimentos, opiniões e valores (BONAVIDES, 2001, p. 206). 
Além disso, o regramento constitucional se caracteriza pela absorção de valores morais e políticos, sobretudo em um sistema de direitos fundamentais autoaplicáveis. Tudo isso sem prejuízo de se reafirmar contemporaneamente a ideia de que o poder deriva do povo, que se manifesta ordinariamente por seus representantes. Toda essa carga simbólica de supremacia e ideal de representação compõe o quadro contemporâneo de status das Constituições, como ícone máximo dos princípios democráticos e de efetivação da justiça. "A esse conjunto de fatores vários autores, sobretudo na Espanha e na América Latina, dão o nome de neoconstitucionalismo" (MENDES \& BRANCO, 2011, p. 62).

Somando-se a essa realidade, e como consequência dela, tem-se proliferado nas maiores democracias do mundo um fenômeno de valorização cada vez maior das Cortes Constitucionais, as Cortes Supremas na chefia do Poder Judiciário, que possuem, entre outras atribuições, a nobre tarefa de zelar pelo ordenamento jurídico e pela "guarda da Constituição". O crescente desprestígio dos órgãos de representação político-democrática, impulsionado principalmente pelos frequentes escândalos de corrupção, reflete-se em uma onda de supervalorização dos meios judiciais.

A análise linguística e socialmente orientada do texto constitucional aqui empreendida pretende, entre outras reflexões, questionar o ideal de máxima representatividade que a Constituição Federal de 1988 tem ostentado desde seu surgimento até os dias de hoje. Nossas considerações recaem, portanto, sobre a problemática que o discurso da representatividade jurídica instaura, a partir do panorama fornecido pelas noções de gênero e estrutura genérica oriundas da ADC. Em outras palavras, que estratégias são mobilizadas para a estruturação genérica de um discurso de representatividade dos anseios do povo na Constituição Federal de 1988? Que vozes estão presentes na construção desse discurso? Quais as estratégias de linguagem postas em cena no desenho das feições do Estado de direito brasileiro? Que representações são mobilizadas? Que exclusões esse discurso legitima?

\section{Significado acional e ADC: o gênero discursivo normativo constitucional em questão}

A Análise de Discurso Crítica é uma abordagem dos fenômenos linguísticos que engloba diversas vertentes, dentre as quais a Teoria Social do Discurso (TSD), de Norman Fairclough, é uma das mais proeminentes. Dada sua notável aceitação e divulgação entre as abordagens críticas da linguagem, tornou-se comum a referência ao pensamento faircloughiano como ADC, prática que, como se pôde perceber em momentos anteriores, está sendo adotada neste trabalho. Desse modo, quando mencionamos $\mathrm{ADC}$ neste trabalho, estamos nos referindo à perspectiva proposta por Fairclough. 
Fairclough (2003) assevera desde o início de seu trabalho que sua proposta de abordagem crítica da linguagem tem um direcionamento interdisciplinar. Sua compreensão do discurso como um momento de práticas sociais, dialeticamente interconectado a outros elementos, tem como uma de suas consequências mais notáveis oferecer um ponto de vista privilegiado acerca das questões de linguagem para estudiosos das diversas áreas das ciências sociais. Em muitas dessas áreas - e o Direito não se diferencia nesse aspecto - frequentemente ocorre o confronto com questões de linguagem e a necessidade de trabalhar com materiais de linguagem, tais como, no caso do Direito, textos escritos, como o são os textos normativos que compõem o ordenamento jurídico.

Para operacionalizar sua proposta analítica, Fairclough parte dos postulados da Linguística Sistêmico-Funcional (LSF) de Halliday (1978), que são apropriados com o intuito de alcançar uma abordagem dos aspectos materiais dos textos profícua para os fins da ADC. Na obra Analysing Discourse (2003), Fairclough realiza uma articulação teórica entre as macrofunções de Halliday e os conceitos de gênero, discurso e estilo, para adotar, ao invés das funções da linguagem, três tipos de significados: o acional, o representacional e o identificacional. Esses três tipos de significados dizem respeito a três principais maneiras de o discurso figurar no interior de práticas sociais: como modos de agir (significado acional), como modos de representar (significado representacional) e como modos de ser (significado identificacional) (RAMALHO \& REZENDE, 2006, p. 59).

Empreendemos uma análise do gênero discursivo normativo constitucional, tomando como instância de análise a Constituição brasileira vigente. Foi adotado o ponto de vista do significado acional, isto é, as formas particulares de ação social por meio dos textos no interior das práticas sociais. Nas palavras de Fairclough, gêneros constituem o aspecto especificamente discursivo de modos de ação e interação no decorrer de eventos sociais (FAIRCLOUGH, 2003, p. 65).

Enquanto modo do discurso que figura em práticas sociais, isto é, como uma faceta da ordem de discurso, um gênero pode ser definido como um mecanismo articulatório que controla o que pode ser usado e em que ordem. Assim, quando se analisa um texto em termos de gênero, focaliza-se a configuração e a ordenação do discurso em termos das práticas sociais articuladas para sua produção. Dentre as categorias analíticas empregadas por Fairclough para o estudo dos gêneros, destacamos a estrutura genérica.

Inicialmente, a abordagem da estrutura genérica de um texto pressupõe a consciência da volatilidade dos gêneros quando abordados in concreto, seu grau de estabilização relativo. Pressupõe que as propriedades de gêneros concretos variam de diferentes maneiras: em escala de atuação, em grau de estabilização 
e homogeneização, em níveis de abstração etc. (RAMALHO \& REZENDE, 2006, p. 62-63).

Dessa forma, ao analisar textos concretos segundo a perspectiva do significado acional, antes de se analisar gênero, analisamos a estrutura genérica, isto é, o modo de articulação dos diferentes gêneros presentes e ausentes no uso abordado em particular, de maneira a perceber como o discurso estudado atua no interior das práticas em que se insere, como ele figura no seio das lutas hegemônicas, com tendência para a estabilização e naturalização de representações e identidades, ou em direção à mudança.

Essa reflexão é muito cara ao Direito e à abordagem do discurso jurídico. Isto porque o Direito sempre conviveu com a perene contradição entre a necessidade de estabilização de seus institutos e categorias - tendo em vista sua inclinação finalística de estabelecimento de uma ordem, da imposição de um ordenamento - e a igual exigência de dinamicidade, com vistas a acompanhar as mudanças ocorridas no todo social. O ideal da ordem jurídica seria refletir a ordem social, em termos mesmo especulares. E, para muitos juristas e operadores do Direito em geral - por uma ingenuidade indefensável ou por uma disposição volitiva condenável -, esse constitui o ideal sempre perseguido ou, pior ainda, alcançado.

A abordagem de um texto em termos de gêneros nos leva a pensar o modo como a forma linguística interioriza e contribui para ações sociais e interações em eventos sociais. A partir dessa constatação, pode-se avaliar um texto particular a partir da escala de atuação do gênero empregado nele. Alguns gêneros são relativamente locais em escala, outros podem ser considerados de escala global (FAIRCLOUGH, 2003, p. 65-66). Dessa forma, podese refletir, acerca do texto normativo constitucional, em termos de qual seria sua escala de atuação e como esse aspecto influenciaria o modo de (inter)ação entre os participantes do evento discursivo em questão, isto é, o Legislador, os cidadãos e o ordenamento jurídico pátrio.

Além disso, a abordagem da estrutura genérica nos leva a refletir acerca da mudança de gêneros e da combinação de gêneros. Como já mencionado anteriormente, não há que se trabalhar com uma tipologia fixa de gêneros do discurso, e sim com a constatação de que gêneros particulares são frutos de combinações de gêneros pré-existentes. O discurso, situado no nível das práticas sociais, caracteriza-se por uma cadeia de eventos (prática), que envolve uma cadeia ou rede de formas comunicativas diferentes, que irão caracterizar uma cadeia de gêneros (FAIRCLOUGH, 2003, p. 66). A análise da cadeia de gêneros constitui mais um passo do estudo da estrutura genérica de um discurso concreto.

Dessa forma, Fairclough (2003, p. 66) aponta passos fundamentais para o procedimento do estudo da estrutura genérica de um texto: 

a) Análise da cadeia de gêneros;
b) Análise da mistura de gêneros em um texto particular;
c) Análise de gênero individual em um texto particular:
c.1) Atividade;
c.2) Relações sociais;
c.3) Tecnologia de comunicação.

Cada um desses passos representa um nível de abordagem da estrutura genérica; do mais amplo ao mais restrito. Para o estudo da Constituição Federal, texto de natureza normativa que, por um lado, apresenta traços formais tão propensos à regularidade e à objetividade; e, por outro, mobiliza, evoca e busca reunir representações sociais tão instáveis quanto às vicissitudes contingenciais da sociedade que lhe cumpre regulamentar, a abordagem da estrutura genérica poderá ser muito frutífera para lançar considerações relevantes acerca do modo de funcionamento desse discurso no contexto das práticas sociais que o envolvem.

No caso do discurso que fornece ocasião para o empreendimento analítico ora em curso, pode-se dizer que os padrões composicionais bastante rígidos e a forte pressão pela estabilização e objetivação das representações postas em cena são marcas que interpelam o analista ao primeiro olhar. $\mathrm{O}$ discurso jurídico-normativo constitucional emerge de instituições fortemente tendentes à fixidez. De fato, a própria estruturação do texto, seu modo de organização e sistematização já prenunciam essa disposição à permanência.

Procuramos demonstrar neste trabalho que, a par da escolha por formas rígidas de estruturação dos textos jurídicos normativos, não é possível esvaziar o sentido ideológico que se radica no interior dessas formas. Ao contrário, até mesmo a escolha por formas de estruturação tão estáveis e homogêneas contribui decisivamente para compreender a norma jurídica constitucional como um produto ideológico. "O domínio do ideológico coincide com o domínio dos signos: são mutuamente correspondentes. Ali onde o signo se encontra, encontra-se também o ideológico. Tudo que é ideológico possui um valor semiótico" (BAKHTIN/ VOLOSHINOV, 2004, p. 32).

Uma marca preliminar dos padrões de estruturação rigorosos diz respeito ao fato de que todo texto normativo produzido no Brasil precisa obedecer à sistemática de organização de matérias 1 MENDES, G. F.;
FORSTER JÜNIOR, N. J. Manual de redação da presidência da república. 2 ed. Brasília: Presidência da República, 2002. expressa no "Manual de Redação da Presidência da República"1, distribuindo-se em: livros, títulos, capítulos, seções, subseções, artigos, incisos, parágrafos, alíneas.

É parte da proposta analítica desenvolvida neste trabalho combalir as estruturas do esqueleto firme em que se apoiam as 
representações mobilizadas nos textos jurídico-normativos, especialmente na redação constitucional; e desvelar o encadeamento de valores, o estabelecimento de fronteiras, as assimetrias e disputas por poder que estão presentes na Constituição, assim como estão presentes em qualquer outro texto com inscrição sócio-histórica; e, mais que isso, reclamar atenção séria para essa problemática, a fim de situar as questões éticas e políticas no centro e no princípio dos estudos da linguagem e, porque não dizer, na dogmática e na ciência jurídicas.

Fairclough (2003), no interesse de traçar o caminho das pedras a ser seguido pelo analista, realizou um escalonamento do grau de estabilização dos gêneros do discurso, sugerindo uma útil diferenciação entre gêneros situados, gêneros deslocados ou desencaixados e pré-gêneros. Tais espécies genéricas, apresentadas em nível crescente de abstração e generalização, constituem instrumentos indispensáveis para o desvelamento da cadeia de gêneros presente em um texto particular. A análise da cadeia de gêneros diz respeito justamente à identificação das espécies genéricas presentes em um texto, dentro dessa escala apresentada por Fairclough (2003). Portanto, trata-se de saber quais gêneros situados, quais gêneros desencaixados e quais pré-gêneros encontram-se presentes no texto em estudo.

Essa tarefa é indissociável do segundo passo no percurso analítico da estrutura genérica: a análise da mistura de gêneros em um texto particular. Isto porque, se o primeiro movimento consiste em identificar, o segundo consiste em avaliar como tais gêneros encontram-se relatados no texto em estudo. Trata-se de saber como os gêneros encontram-se combinados, se de forma competitiva, hierárquica, alternada, ou justaposta.

Tendo como base a Constituição, pode-se dizer que o gênero situado em questão é o gênero normativo, o texto de lei, com os traços básicos que já foram mencionados aqui. No que diz respeito aos pré-gêneros, a análise adquire novo impulso. $O$ texto constitucional, dada sua finalidade de dar as feições do Estado de direito, apresenta um pré-gênero principal que o atravessa de ponta a ponta: a descrição. Basicamente, o texto descreve quais os termos da ordem jurídica que se sobreleva à sociedade brasileira, lança os atributos, as características, e define os institutos que irão sustentar a ordem da nação.

A par de ser o mais proeminente, a descrição não é o único pré-gênero que compõe a cadeia de gêneros no discurso constitucional. Articulada à descrição, encontra-se também a injunção. A estrutura genérica do texto constitucional caracteriza-se por uma mescla de descrição e injunção, em que a primeira apresenta clara proeminência e manifesta-se no uso de verbos impessoais, de formas sintáticas de oração sem sujeito ou de processos de indeterminação. 
Descrição

Art. $2^{\circ}$ São Poderes da União, independentes e harmônicos entre si, o Legislativo, o Executivo e o Judiciário.

Art. $3^{\circ}$ Constituem objetivos fundamentais da República Federativa do Brasil [...]

Art. $6^{0}$ São direitos sociais a educação, a saúde, a alimentação, o trabalho, a moradia, o lazer, a segurança, a previdência social, a proteção à maternidade e à infância, a assistência aos desamparados, na forma desta Constituição.

Art. 17. É livre a criação, fusão, incorporação e extinção de partidos políticos, resguardados a soberania nacional, o regime democrático, o pluripartidarismo, os direitos fundamentais da pessoa humana e observados os seguintes preceitos [...]

\section{Injunção}

Art. $1^{\circ}[\ldots]$ Parágrafo único. Todo o poder emana do povo, que o exerce por meio de representantes eleitos ou diretamente, nos termos desta Constituição.

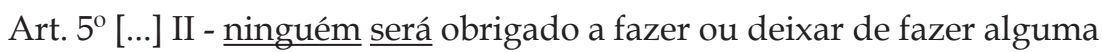
coisa senão em virtude de lei;

Art. $5^{\circ}[\ldots]$ XLI - a lei punirá qualquer discriminação atentatória dos direitos e liberdades fundamentais;

Art. $4^{\circ}[\ldots]$ Parágrafo único. A República Federativa do Brasil buscará a integração econômica, política, social e cultural dos povos da América Latina, visando à formação de uma comunidade latino-americana de nações.

Como se pode observar pelos trechos apontados, há uma diferença, mesmo que tênue, entre as construções linguísticas dos dois conjuntos de textos apontados. No primeiro caso, em geral, são formas sintáticas de orações sem sujeito ou de sujeito indeterminado. No segundo, há sempre um sujeito que "age" nas estruturações sintáticas das orações: "o povo", "ninguém", "todos", 
"a lei", "a República Federativa do Brasil". São as formas de ação do Estado sobre a sociedade, sua relação com o seu outro, os cidadãos.

Na análise da mistura de gêneros, portanto, o aspecto de maior relevância - que atravessa toda a estruturação genérica do discurso jurídico constitucional - é o grau de estabilização e homogeneização das formas, emblemático do impulso em direção à fixidez.

O último passo no percurso analítico da estrutura genérica, a análise do gênero individual, proporciona considerações nesse mesmo direcionamento. $\mathrm{O}$ estudo do gênero individual empregado em um texto particular inclui a abordagem de três aspectos: atividade, relações sociais e tecnologias de comunicação. Passemos ao estudo desses aspectos, tendo por base a prática discursiva constitucional.

Já foi mencionado que os eventos sociais dizem respeito a atividades acima de tudo, tanto em seu aspecto discursivo como não discursivo. Por conta disso, uma distinção preliminar entre eventos sociais em que a atividade de natureza discursiva predomina, em comparação com outras nas quais o discurso, embora presente, constitui elemento secundário apresenta desmembramentos importantes. Esta primeira distinção já se nos apresenta frutífera para a abordagem crítica do discurso jurídico tomado como base para nossa análise: o texto normativo, isto é, a lei (tomada em sentido amplo); o gênero normativo em geral, do qual a Constituição é uma espécie.

Qual seria, cumpre questionar, a predominância de atividade nos eventos sociais em que a lei é posta em xeque? Seria a atividade discursiva? De fato, a lei é primordialmente, e originalmente, discurso (e esta afirmação traz consigo desdobramentos muito importantes). Constitui a lei um texto ou um conjunto de textos, uma série ordenada e sistemática de textos que são lidos, escritos, pronunciados, proferidos, remetidos, distribuídos, aplicados. Sob esse ponto de vista, incontestavelmente, a lei é discurso. O raciocínio nessa direção nos faria afirmar a predominância da atividade discursiva no que diz respeito aos gêneros normativos.

Contudo, a atividade predominante no discurso jurídico normativo não é a mesma do discurso jurídico dos operadores do direito, por exemplo. A lei exerce um papel muito específico no seio da sociedade, possui, por esse motivo, um poder diferenciado, força cogente e inescusável. A lei se sobrepõe às relações sociais, regendo-as, impondo-lhes limitações, fronteiras (para usar uma expressão mais familiar aos estudos culturais e, portanto, capaz de lançar nova luz sobre o modo como o discurso jurídico "age" sobre a sociedade).

Estas fronteiras demarcadas pelos dispositivos de lei, aqui em questão os dispositivos constitucionais, não são sugeridas ou apontadas, são impostas realmente. Impostas, por constituírem fruto de um processo legislativo legítimo, previamente autorizado 
pela lei ou pela constituição, que tem sua fonte de legitimidade no povo e que se realiza por meio de um sistema republicano democrático representativo. Para além de questionar essa representatividade política - noção que constitui objeto de inúmeros estudos em diversos ramos do conhecimento: Ciência Política, Teoria do Estado, Ciência Jurídica, Ciências Sociais, entre muitos outros -, o presente trabalho propõe questionar a representatividade discursiva, isto é, o discurso que constitui a base para todo esse processo.

A questão da predominância de uma ou outra atividade é importante nesta discussão porque pode ser muito esclarecedora da atitude ética de quem se debruça sobre o problema. Isto porque afirmar categoricamente que predomina a atividade de natureza jurídica - afinal a Constituição não é discurso, simplesmente, como as demais produções culturais humanas; ela é, na verdade, uma ordem positiva, que traduz, reflete a ordem social - implica uma postura objetivista de compreensão seja do direito, seja do discurso, seja da ordem social. Implica pressupor uma ordem natural, posta como necessária, que pode ser simplesmente transposta para o texto da lei, já que é anterior à linguagem.

É possível traçar um paralelo entre os propósitos de atividade da Constituição, enquanto gênero individual aqui tratado, com a análise da mistura de gêneros outrora feita. Segundo esta, o pré-gênero descritivo surge em proeminência no texto constitucional, combinado com ocorrências narrativas de menor destaque. A estruturação genérica possui, portanto, um direcionamento privilegiado para a exposição, descrição e enumeração dos termos de uma ordem: a ordem jurídica constitucional brasileira. Em termos de gênero e escolhas de linguagem, o Estado de direito não é "construído" discursivamente, mas sim "descrito", representado (em termos especulares).

Um tipo de orientação como esta poderia nos dirigir, de imediato, ao entendimento de que o propósito comunicativo encontra-se privilegiado no nosso gênero de estudo. Afinal, trata-se de dizer, de comunicar aos interessados, os cidadãos, o povo, como é o Estado, quais suas características. Queremos, contudo, desenvolver aqui uma compreensão voltada justamente para o contrário. Pretendemos demonstrar que a construção do discurso constitucional se dá em meio a possibilidades de escolhas éticas, da mesma maneira que qualquer outra forma de discurso, tendo em vista que as decisões de sentido não seguem uma lei natural, sendo tão somente o resultado de elementos contingenciais que definem uma configuração hegemônica específica e constituem um momento particular das lutas por representações. Os significados mobilizados não são verdades pré-existentes à linguagem, mas empreendimentos de representação que se manifestam em estratégias de linguagem como estas aqui analisadas do ponto de vista da estrutura genérica. O propósito da atividade no gênero 
constitucional aqui em estudo é muito mais estratégico, porque dirigido à legitimação de formas de controle social por meio do discurso.

O segundo aspecto da análise do gênero individual diz respeito ao estudo das relações sociais que são travadas entre os sujeitos envolvidos na prática discursiva em questão. Em conformidade com o raciocínio que vem sendo desenvolvido até aqui se pode facilmente constatar um elevado grau de hierarquia e distanciamento social entre os sujeitos envolvidos no processo. Constitui um traço marcante na configuração discursiva dos textos normativos - e, neste aspecto, da Constituição, em particular, em função do seu status diferenciado em meio ao ordenamento jurídico - a afirmação da força institucional de que promana o discurso, em detrimento daqueles que a ele se submetem. Há um sujeito autorizado e detentor da voz, que não torna possível o diálogo.

Nessa linha de raciocínio, atinge-se, por fim, o último aspecto do estudo dos gêneros individuais, as tecnologias de comunicação. Dentro da classificação proposta por Fairclough (2003), seria possível enquadrar a prática do discurso constitucional como comunicação unidirecional não mediada. Unidirecional porque não oferece ocasião para o diálogo entre as partes - pelo menos não um diálogo imediato. Não mediada porque, a priori, não consiste em um discurso especializado para tecnologias de comunicação mais elaboradas.

Esta simples classificação é, contudo, problemática, como toda taxionomia. Isso porque os meios de comunicação institucional têm se diversificado muito em função da oferta de novas formas de transmissão de informação. Exemplos disso são as duas leis recentemente sancionadas no Brasil, pela presidenta Dilma Rousseff, voltadas para aprimorar a transparência dos atos da administração pública em relação a seus usuários, os cidadãos: a lei de acesso à informação (Lei $n^{\circ} 12.527 / 2011$ ) e a lei que cria a comissão da verdade (Lei $\left.n^{\circ} 12.528 / 2011\right)$. Tem-se construída, portanto, uma ponte de acesso para a promoção de um diálogo entre indivíduos e instituições na contemporaneidade, que pode e deve ser merecedor de atenção renovada por parte dos críticos da sociedade e do discurso.

Hoje, a Constituição pode ser acessada através da internet a qualquer momento e, da mesma forma, os atos institucionais que dizem respeito a ela. Os impactos da mediação sobre a ordem do discurso jurídico constitucional na atual sociedade da informação constitui uma temática possível e relevante para prováveis pesquisas. As proposições de Emendas à Constituição, nas Casas do Congresso Nacional, estão disponíveis ao domínio público por meio da internet e da televisão. O julgamento acerca da constitucionalidade das leis e atos normativos pelos membros da Suprema Corte brasileira são televisionados em tempo real 
para todo o país. Além disso, a comunicação rápida e livre por meio das redes sociais tem sido um portal de acesso à intervenção social e política, sinalizando a formação de um novo tipo de protagonismo político do povo.

Trata-se, como se pode observar nas considerações feitas aqui, de uma problemática extremamente complexa, que pode se submeter a análises com vários direcionamentos. Pelo que foi exposto, pode-se perceber que o desvendamento do modo de estruturação genérica da Constituição tem muito a contribuir para a compreensão de como esse discurso atua em meio às disputas por poder e representação, principalmente no que concerne às escolhas linguísticas que antecedem os padrões rigorosos de composição empregados nesse texto, em função do seu ideal de objetividade.

Não se deseja, com tais palavras, questionar propriamente o princípio democrático - embora este fosse, talvez, um desejo legítimo - da possibilidade de intervenção do povo sobre a determinação da ordem das leis. Trata-se de descortinar o exercício do poder por meio do discurso, materializado em escolhas linguísticas como essas.

\section{Conclusão}

Pelas considerações até aqui esboçadas, foi possível perceber que a visão de gêneros operacionalizada na ADC é especialmente marcada pela mobilidade e dialogicidade. Não há que se trabalhar com uma tipologia fixa dos gêneros, uma vez que as formas de ação e interação por meio dos textos no interior das práticas sociais são tão voláteis quanto ao contexto sociocultural no qual elas ocorrem.

Há uma relação de proximidade dialética muito forte entre gêneros e práticas sociais, "de tal modo que mudanças articulatórias em práticas sociais incluem mudanças nas formas de ação e interação, ou seja, nos gêneros discursivos" (RAMALHO \& REZENDE, 2006, p. 62), da mesma maneira que a mudança genérica pode contribuir para a mudança social por meio do discurso. Resumidamente, portanto, no âmbito do significado acional, os gêneros constituem formas de ação por meio do discurso, modos pelos quais discursos agem no interior das práticas sociais concretas.

A análise dos dados demonstra que o desvendamento do modo de estruturação genérica da Constituição tem muito a contribuir para a compreensão de como esse discurso atua em meio às disputas por poder e representação, principalmente no que concerne às escolhas linguísticas que antecedem os padrões rigorosos de composição empregados nesse texto, em função do seu ideal de objetividade.

As escolhas que antecedem a conformação genérica dos textos da Lei em geral - isto porque muitas das reflexões apli- 
cam-se à Lei em sentido amplo - e da redação constitucional em particular, tomada no presente estudo como exemplo mais emblemático e, porque não dizer, problemático, das ocorrências destacadas, refletem e refratam um posicionamento ideológico e um direcionamento político claramente ancorados nos anseios do contexto histórico e social em que foram geradas. Mais que isso, tais ocorrências trazem impressas em si marcas sensíveis da disparidade das posições de poder dos sujeitos envolvidos no processamento desse discurso, assim como os rastros da luta hegemônica travada entre eles.

Uma das considerações importantes a serem lançadas pelo presente estudo diz respeito ao entendimento de que o Estado de direito, os elementos que o constituem, as regras que regem seu funcionamento são construções sócio-histórico-discursivas, facetas de processos sociais mais amplos. Por esse motivo, a investigação crítica da problemática de sua discursividade reclama de forma precípua a consideração da dimensão ético-política desse empreendimento de linguagem. É na persecução desse olhar sobre a formação discursiva da ordem jurídico-normativa constitucional brasileira que se centra este estudo, procurando compreender as fronteiras estabelecidas na edificação dessa ordem, as escolhas que antecedem a construção dos objetos de linguagem, suas implicações sociais, por intermédio da investigação linguística.

Para além desses objetivos, a orientação crítica da proposta de Análise do Discurso de linha faircloughiana relaciona-se ao seu ideal transformador. Assim, é notadamente no caráter emancipatório da disciplina que se acentua sua orientação crítica. Para o estudo de práticas simultaneamente sociais e discursivas tão complexas, tais como a prática jurídica - especificamente neste estudo a prática jurídico-normativa constitucional -, este horizonte oferecido pela ADC pode constituir um contributo indispensável. Segundo esse horizonte, a linguagem nos convida continuamente a intervir nela, com o fim de desvelar posicionamentos ideológicos, relações de dominação e esquiva, disputas por poder, que são travadas em seu interior. A proposta de intercâmbio dialógico entre estruturas e eventos, pela via das práticas, proporciona uma postura revolucionária acerca da linguagem, como espaço privilegiado de intervenção sobre a sociedade, potencialmente geradora da transformação social.

\footnotetext{
Abstract

The study proposed here turns to the construction of normative constitutional legal discursive genre, from its ideological dimension, seeking to understand how the use of particular linguistic forms contributes to establishing and sustaining relations of domination within and outside spe-
} 
ech (Thompson, 2009). It takes as theoretical reference the $A D C^{\prime}$ 's understanding of discourse as a moment of social practices, dialectically interconnected with other elements. Besides $A D C$, this study seeks to develop a dialogue with transdisciplinary research historical context in which it was gestated our current Constitution, the Constitutional Law and the General Theory of the State, especially when it comes to social and legal constitutions value in contemporary. For the operationalization of the analysis just outlined, we take as an instance discursive analysis the 1988 Federal Constitution, legislation that opens the normative rule of Brazilian law, as well as we adopt by reference the discussion that Fairclough (2003) does about the notion of actional meaning and the analytical category generic structure.

Keywords: Critical Discouse Analysis; actional meaning; generic structure; Federal Constituition.

\section{REFERÊNCIAS}

BAKHTIN, Mikhail. Marxismo e filosofia da linguagem: problemas fundamentais do método sociológico na ciência da linguagem. São Paulo: Editora Hucitec, 2004.

BONAVIDES, Paulo. Ciência Política. 10ª ed. São Paulo: Malheiros Editores, [1967] 2001.

Constituição da República Federativa do Brasil de 1988.

FAIRCLOUGH, Norman. Discurso e mudança social. Brasília: Editora Universidade de Brasília, 2001.

Analysing discourse: textual analysis for social research. London: Routledge, 2003.

FAUSTO, Boris. História concisa do Brasil. $3^{\text {a }}$. ed. São Paulo: EdUSP, 2008.

FERREIRA, Ruberval. Guerra na língua: mídia, poder e terrorismo. Fortaleza: EdUECE, 2007.

MENDES, Gilmar Ferreira; BRANCO, Paulo G. Gonet. Curso de direito constitucional. 6a. ed. São Paulo: Saraiva, 2011.

MENDES, G. F.; FORSTER JÚNIOR, N. J. Manual de redação da presidência da república. 2a . ed. Brasília: Presidência da República, 2002. MIRANDA, Jorge. Teoria do estado e da constituição. Rio de Janeiro: Editora Forense, 2002.

RAMALHO, Viviane; RESENDE, Viviane de Melo. Análise de discurso crítica. São Paulo: Contexto, 2006. 
REALE, Miguel. Teoria do direito e do estado. São Paulo: Saraiva, [2000] 2010.

THOMPSON, John B. Ideologia e cultura moderna: teoria social crítica na era dos meios de comunicação de massa. Petrópolis: Vozes, 2009. 